immunosuppressive treatments may modify gut microbiota in SSc. Overall these findings support the involvement of altered immune recognition of specific gut bacteria in early SSc.

Disclosure of Interests: Anna-Maria Hoffmann-Vold Grant/research support from: Boehringer Ingelheim, Consultant of: Boehringer Ingelheim, Actelion, Bayer, GlaxoSmithKline, Speakers bureau: Boehringer Ingelheim, Actelion, Roche, Kristofer Andréasson: None declared, Simen Hyll Hansen: None declared, Simon Midtvedt: None declared, Håvard Fretheim: None declared, Henriette Didriksen Consultant of: Actelion, Torhild Garen: None declared, Espen Bækkevold: None declared, Øyvind Midtvedt: None declared, Roger Hesselstrand: None declared, Brian K Chung: None declared, Øyvind Molberg: None declared

DOI: 10.1136/annrheumdis-2020-eular.5481

\section{THU0349 THE RELATIONSHIP BETWEEN DISEASE ACTIVITY AND SEVERITY IN SYSTEMIC SCLEROSIS: A PROSPECTIVE ANALYSIS OF 278 PATIENTS}

Y. Yalçınkaya ${ }^{1}$, N. Aliyeva ${ }^{1}$, S. Amikishiyev ${ }^{1}$, Y. Cagatay ${ }^{1}$, B. Artim-Esen ${ }^{1}$, A. Gul ${ }^{1}$, L. Ocal ${ }^{1}$, M. Inanc ${ }^{1} .{ }^{1}$ Istanbul University, Istanbul Medical Faculty, Department of Internal Medicine, Division of Rheumatology, Istanbul, Turkey

Background: Evaluating disease activity and severity in systemic sclerosis (SSc) is crucial to define the patients who are candidate for treatment options. Objectives: We aimed to investigate the relationship between disease activity and severity in SSc in a large cohort.

Methods: This is a cross-sectional prospective analysis of 278 (253 females) patients fulfilling ACR/EULAR (2013) classification criteria for SSc. Disease activity and severity were calculated seperately for cutaneous subsets (EscSG and Medsger). The patients were grouped as inactive if EscSG score $=0$, mildly active if EscSG score $>0<3$, active if EscSG score $\geq 3$.

Results: The mean age, duration of Raynaud's and non-Raynaud features were $48.5 \pm 13.1,12.1 \pm 9.8$ and $8.3 \pm 7.5$ years respectively. Characteristics of the SSc patients were summarized in table-1.

\section{Table-1: Characteristics of SSc patients}

\begin{tabular}{|l|c|}
\hline & $\begin{array}{c}\text { All patients } \\
\mathbf{n = 2 7 8}(\%)\end{array}$ \\
\hline ANA & $223(80.2)$, \\
\hline anti-centromer & $128(46.0)$ \\
\hline anti -Scl70 & $39(14.0)$ \\
\hline Anti-RNApol3 & $29 / 165(17.6)$ \\
\hline limited cutaneous pattern & $143(51.4)$ \\
\hline diffuse cutaneous pattern & $135(48.6)$ \\
\hline digital ulcers & $101(36.3)$ \\
\hline Synovitis & $56(20.1)$ \\
\hline flexion contractures & $81(29.1)$ \\
\hline Myositis & $40(14.4)$ \\
\hline lung involvement & $140(50.4)$ \\
\hline PAH & $9(3.2)$ \\
\hline GIS inolvement & $166(59.2)$ \\
\hline renal crisis & $8(2.9)$ \\
\hline Immunosuppressives & $173(62.2)$ \\
\hline Steroids & $156(56.1)$ \\
\hline specific vasodilatory drugs & $47(16.9)$ \\
\hline
\end{tabular}

Ninety-three (34\%) and $151(54 \%)$ patients were evaluated as having active and mildly active disease. Only $34(12 \%)$ patients had inactive disease. The patients with diffuse cutaneous involvement (dcSSc) who were active had higher modified Rodnan Skin score(mRSS) and severity scores of general, skin and joint-tendon involvements; the patients who had mildly active disease also had higher scores of mRSS and severity scores of skin compared to those with inactive disease (table-2). The patients with limited cutaneous involvement (IcSSc) who were assessed as having active disease had higher mRSS and higher severity scores of general, skin, peripheral vascular, lung, joint-tendon and gastrointestinal involvements; the patients who had mildly active disease also had higher scores of mRSS and severity scores of skin, lung, joint-tendon and gastrointestinal involvements compared to those with inactive disease (table-2).

\begin{tabular}{|c|c|c|c|c|c|c|c|c|}
\hline & \multicolumn{4}{|c|}{ deSSc } & \multicolumn{4}{|c|}{ leSSc } \\
\hline & $\begin{array}{c}\text { inactive } \\
n=7\end{array}$ & $\begin{array}{c}\text { mildly active } \\
\mathrm{n}=72\end{array}$ & $\begin{array}{l}\text { active } \\
n=64\end{array}$ & tp & $\begin{array}{r}\text { inactive } \\
n=27\end{array}$ & $\begin{array}{c}\text { mildly active } \\
\mathrm{n}=79\end{array}$ & $\begin{array}{l}\text { active } \\
\mathrm{n}=29\end{array}$ & tp \\
\hline mRSS & $7,0 \pm 3,6^{*}$ & $16,3 \pm 7,6^{* *}$ & $20,4 \pm 8,4^{*}$ & 80.001 & $4,0 \pm 4,1^{*}$ & $7,9 \pm 5,1^{*}$ & $9,9 \pm 7,5^{*}$ & $<0.001$ \\
\hline \multicolumn{9}{|l|}{ Severity Score } \\
\hline General & $1,0 \pm 1,6$ & $0,4 \pm 0,7^{*}$ & $0,8 \pm 0,8^{*}$ & 0.004 & $0,4 \pm 0,6^{*}$ & $0,4 \pm 0,6$ & $0,7 \pm 0,7^{*}$ & 0.004 \\
\hline PVI & $1,5 \pm 0,6$ & $1,8 \pm 0,8$ & $2,1 \pm 0,9$ & Ns & $1,3 \pm 0,6^{*}$ & $1,6 \pm 0,7^{* *}$ & $2,1 \pm 0,9^{*}$ & 80.001 \\
\hline Skin & $0,8 \pm 0,4^{*}$ & $1,7 \pm 0,7^{* *}$ & $1,8 \pm 0,7^{*}$ & 0.003 & $0,7 \pm 0,5^{*}$ & $1,1 \pm 0,4^{* *}$ & $1,2 \pm 0,6^{*}$ & 80.001 \\
\hline Joint tendon & $0,5 \pm 0,8^{*}$ & $1,5 \pm 1,0$ & $1,9 \pm 1,3^{*}$ & 0.023 & $0,3 \pm 0,7^{*}$ & $1,0 \pm 1,0$ & $1,2 \pm 1,1^{*}$ & 0.003 \\
\hline Myositis & $0,3 \pm 0,8$ & $0,2 \pm 0,4$ & $0,2 \pm 0,5$ & Ns & $0,1 \pm 0,6$ & $0,1 \pm 0,4$ & $0,2 \pm 0,5$ & $\mathrm{NS}$ \\
\hline GIS & $0,3 \pm 0,5$ & $0,7 \pm 0,6$ & $0,7 \pm 0,6$ & Ns & $0,3 \pm 0,5^{*}$ & $0,6 \pm 0,5^{* *}$ & $0,7 \pm 0,5^{*}$ & 0.005 \\
\hline Lung & $1,0 \pm 0,63$ & $1,3 \pm 1,1$ & $1,6 \pm 1,4$ & Ns & $0,3 \pm 0,7^{*}$ & $1,2 \pm 1,0^{* *}$ & $1,5 \pm 1,1^{*}$ & $<0,001$ \\
\hline Heart & $0,2 \pm 0,4$ & $0,1 \pm 0,6$ & $0,1 \pm 0,5$ & NS & $0,0 \pm 0,0$ & $0,1 \pm 0,5$ & $\underset{2}{0,04 \pm 0,}$ & NS \\
\hline Renal & $0,0 \pm 0,0$ & $0,0 \pm 0,0$ & $0,9 \pm 0,46$ & Ns & $0,0 \pm 0,0$ & $0,1 \pm 0,6$ & $0,0 \pm 0,0$ & Ns \\
\hline
\end{tabular}

Conclusion: One third of our cohort was found to have active disease despite treatment and only $12 \%$ had inactive disease. Skin involvement and severity of different organs were shown to be higher in patients with active disease in both cutaneous subsets, together with severity of lung, peripheral vascular and gastrointestinal involvements in active IcSSc. LcSSc and dcSSc patients who had mildly active disease also had severe disease similar to those with active patients. Disease activity and severity should be assessed as separate measurements to highlight the course of the disease and may guide to the management of patients with SSc.

Disclosure of Interests: None declared

DOI: 10.1136/annrheumdis-2020-eular.6129

\section{THU0350 LOGOPEDIC TESTING IN SSC PATIENTS REVEALS HIGH FREQUENCY OF OROPHARYNGEAL DYSFUNCTION: A MONOCENTRIC EXPERIENCE}

M. Wirths ${ }^{1}$, O. Hudowenz2, U. Hoffmann ${ }^{3}$, U. Müller-Ladner ${ }^{2}$, U. Lange ${ }^{2}$ P. Klemm². 'Justus Liebig University Gießen, Campus Kerckhoff, Rheumatology, Immunology, Osteology and Physical Medicine, Bad Nauheim, Germany; ${ }^{1}$ Justus Liebig University Gießen, Campus Kerckhoff, Rheumatology, Immunology, Osteology and Physical Medicine, Bad Nauheim, Germany; ${ }^{3}$ Logopädische Praxis Ulrike Hoffmann, Bad Nauheim, Germany

Background: Up to $98 \%$ of patients with systemic sclerosis (SSc) show involvement of the gastrointestinal system (GI) [1]. While meteorism, heartburn and GI dysmotility are very common and accessible to pharmacologic treatment on an evidence based level [1-3], checking for oropharyngeal dysfunction is usually not part of the standard diagnostic algorithm. However, in a survey of the German Network for Systemic Sclerosis (DNSS) patients reported coughing and/ or a sore voice in up to $78 \%$ [1]. As impairment in speaking or swallowing for example does not only substantially reduce quality of life, it can also be very stigmatizing. In addition, the usual prokinetic therapy of Gl-involvement, e.g. metoclopramide, does not appear to improve these symptoms. As the first step to approach this problem is the qualitative and quantitative description, we evaluated the oropharyngeal function in our cohort of SSc patients by detailed logopedic assessment.

Objectives: To evaluate the frequency and type of oropharyngeal dysfunction e.g. swallowing or speaking, in patients with SSc and to elucidate the correlating and associated factors, e.g. disease duration or modified Rodnan Skin Score.

Methods: After obtaining written consent, oropharyngeal function using a standardized assessment protocol was evaluated in patients with SSc fulfilling the ACR/EULAR criteria by a speech therapist. Furthermore, we investigated whether oropharyngeal dysfunction is associated with patients' characteristics. In addition, all patients received instruction for a training program to treat their individual oropharyngeal dysfunction.

Results: 37 patients with d/ISSc were assessed for eligibility. 34 patients met the inclusion criteria ( 3 patients did not speak German) and written consent was obtained.

Oropharyngeal dysfunction (impairment of speaking, swallowing, breathing or oropharyngeal muscle function) was found in 29 of $34(85 \%)$ of both $1 / \mathrm{dSSc}$ patients. Neither the subtype of SSc, disease duration nor mRSS were significantly correlated with oropharyngeal dysfunction in general. Only GI involvement in general was associated with oropharyngeal dysfunction.

After logopedic therapy, 28 of the 34 (82\%) patients with oropharyngeal dysfunction reported a benefit after 3 days of training and were motivated to continue logopedic training at home. 


\begin{tabular}{lccc}
\hline Oropharyngeal dysfunction & $\begin{array}{c}\text { Present } \\
(\mathrm{n}=29)\end{array}$ & $\begin{array}{c}\text { absent } \\
(\mathrm{n}=5)\end{array}$ & p-values $\left(\mathrm{x}^{2}\right.$-test $)$ \\
\hline dcSSc & 8 & 0 & 0,027 \\
IcSSc & 22 & 4 & 0,027 \\
disease duration (mean) & $12,7 \mathrm{y}$ & $12 \mathrm{y}$ & 0,462 \\
mRSS $<$ r & 9 & 2 & 0,322 \\
mRSS $>4$ & 20 & 3 & 0,322 \\
Raynauds syndrom & 29 & 5 & 0,673 \\
digital ulcers & 19 & 2 & 0,812 \\
lung fibrosis & 11 & 2 & 0,596 \\
eosophageal dilatation & 15 & 2 & 0,566 \\
eosophageal dysmotility & 19 & 0 & 0,015 \\
Gl-involvement & 23 & 1 & 0,007 \\
\hline
\end{tabular}

Conclusion: Logopedic assessment revealed a high incidence of oropharyngeal dysfunction in our cohort of SSc patients. Oropharyngeal dysfunction was not associated with disease duration, skin- or lung-involvement or dcSSc/lcSSc differentiation. A logopedic training program seems to be of benefit for this currently not pharmacologically treatable problem.

References:

[1] Schmeiser T, Saar P, Jin D, Noethe M, Müller A, Soydan N, et al. Profile of gastrointestinal involvement in patients with systemic sclerosis. Rheumatol Int 2012;32:2471-8. doi:10.1007/s00296-011-1988-6.

[2] Boeckxstaens GE, Bartelsman JFWM, Lauwers L, Tytgat GNJ. Treatment of GI dysmotility in scleroderma with the new enterokinetic agent prucalopride. Am J Gastroenterol 2002;97:194-7. doi:10.1016/S0002-9270(01)03958-2.

[3] Mercado U, Arroyo de Anda R, Avendaño L, Araiza-Casillas R, Avendaño-Reyes M. Metoclopramide response in patients with early diffuse systemic sclerosis. Effects on esophageal motility abnormalities. Clin Exp Rheumatol 2005;23:685-8.

Disclosure of Interests: Miriam Wirths: None declared, Ole Hudowenz: None declared, Ulrike Hoffmann: None declared, Ulf Müller-Ladner Speakers bureau: Biogen, Uwe Lange: None declared, Philipp Klemm Consultant of: Lilly, Medac DOI: 10.1136/annrheumdis-2020-eular.3467

\section{THU0351 MUSCLE INVOLVEMENT IN PATIENTS WITH SYSTEMIC SCLEROSIS AND ANTI-PM/SCL+ ANTIBODIES IS ASSOCIATED WITH CARDIAC AND PULMONARY INVOLVEMENT. ANALYSIS OF THE MULTICENTRE EUSTAR COHORT.}

M. G. Lazzaroni ${ }^{1}$, S. Zingarelli ${ }^{1}$, P. Airò ${ }^{1}$, Y. Allanore ${ }^{2}$, O. Distler ${ }^{3}$ on behalf of EUSTAR co-authors. ${ }^{1}$ ASST Spedali Civili of Brescia, University of Brescia, Brescia, Italy; ${ }^{2}$ University Paris Descartes and Cochin Hospital, Paris, France; ${ }^{3}$ University Hospital Zurich, Zurich, Switzerland

Background: Anti-PM/Scl antibodies positivity has been associated with frequent skeletal muscle involvement in patients with Systemic Sclerosis (SSc) in different studies, including the EUSTAR cohort (1). Moreover, although myositis has been previously associated with heart involvement in SSc patients (2), this issue has never been explored among anti-PM/Scl+ patients.

Objectives: To evaluate the cardiac involvement in anti-PM/Scl patients with SSc in the large multicentre EUSTAR database, with focus on the subgroup of patients with muscle involvement.

Methods: Patients from the EUSTAR database were included when the item anti-PM/Scl was fulfilled in at least one visit.

Results: Anti-PM/Scl status was available in 7,353 SSc patients from EUSTAR database: 295 were anti-PM/Scl+. After exclusion of 151 patients with multiple autoantibody positivity, 144 anti-PM/Scl + patients were compared with 7,058 anti-PM/Scl- patients. Among them, 3,120 (44.2\%) were positive for ACA, 2,361 (33.5\%) for anti-Topo I and 274 (3.88\%) for anti-RNAP3.

Regarding the specific cardiac outcomes, in the anti-PM/Scl+ as compared to the anti-PM/Scl- group, a decreased rate of elevated SPAP at ECHO was recorded (12.8\% vs $25.0 \%$, p:0.001), while no differences were observed in the frequency of conduction blocks (26.2\% vs $23.7 \%$, p:0.526), abnormal diastolic function (33.9\% vs $36.4 \%$, p:0.582), pericardial effusion (10.2\% vs $10.9 \%, \mathrm{p}: 1.000)$ and LVEF $\leq 50 \%$ (4.76\% vs $6.11 \%$, p:0.818). In multivariate analysis, adjusted for age at disease onset, sex, and disease duration, the negative association of anti-PM/ $\mathrm{Scl}$ with elevated SPAP was not confirmed (p:0.061).

When comparing anti-PM/Scl+ patients with $(n=47)$ and without $(n=87)$ CK elevation, the former group had a higher frequency of conduction blocks $(43.2 \%$ vs $17.5 \%$, p:0.005; OR $95 \% \mathrm{Cl} 3.47,1.51-7.97)$ and left ventricular dysfunction, both diastolic (45.6\% vs 27.2\%, p:0.050; OR 95\% Cl 2.25, 1.05-4.81) and systolic (LVEF $\leq 50 \% 13.3 \%$ vs $0 \%$, p:0.018; OR 95\% Cl 16.8, 0.87-324). Moreover, anti-PM/Scl+ patients with CK elevation had significantly increased rate of lung fibrosis on HRCT (p:0.045), intestinal symptoms (p:0.017), joint contractures (p:0.045) and tendon friction rubs (p:0.034)

Conclusion: In the largest series of anti-PM/Scl positive SSc patients so far reported, muscle involvement in anti-PM/Scl+ patients (defined as increased serum $\mathrm{CK}$ ) seems to represent a marker of a more severe disease phenotype, including a higher frequency of cardio-pulmonary involvement.

References:

[1] Lazzaroni MG, et al. Ann Rheum Dis 2018. 77 (2), 421-2.

[2] Follansbee WP, et al. Am Heart J 1993. 125: 194-203.

Acknowledgments: Authors would like to thank the patients' association GILS (Gruppo Italiano Lotta Sclerodermia) for the grant that supported the project Disclosure of Interests: Maria Grazia Lazzaroni: None declared, Stefania Zingarelli: None declared, Paolo Airò: None declared, Yannick Allanore Grant/ research support from: BMS, Inventiva, Roche, Sanofi, Consultant of: Actelion Bayer AG, BMS, BI, Oliver Distler Grant/research support from: Grants/Research support from Actelion, Bayer, Boehringer Ingelheim, Competitive Drug Development International Ltd. and Mitsubishi Tanabe; he also holds the issued Patent on mir-29 for the treatment of systemic sclerosis (US8247389, EP2331143). Consultant of: Consultancy fees from Actelion, Acceleron Pharma, AnaMar Bayer, Baecon Discovery, Blade Therapeutics, Boehringer, CSL Behring, Catenion, ChemomAb, Curzion Pharmaceuticals, Ergonex, Galapagos NV, GSK Glenmark Pharmaceuticals, Inventiva, Italfarmaco, iQvia, medac, Medscape, Mitsubishi Tanabe Pharma, MSD, Roche, Sanofi and UCB, Speakers bureau: Speaker fees from Actelion, Bayer, Boehringer Ingelheim, Medscape, Pfizer and Roche

DOI: 10.1136/annrheumdis-2020-eular.3525

\section{THU0352 DIAGNOSTIC PERFORMANCES OF HAND ULTRASOUND PARAMETERS AND THEIR IMPACT ON THE 2013 ACR/EULAR CLASSIFICATION CRITERIA FOR SYSTEMIC SCLEROSIS.}

M. De Saint Riquier ${ }^{1}$, A. Ballerie ${ }^{2}$, F. Robin $^{3}$, N. Belhomme ${ }^{4}$, C. Cazalets ${ }^{4}$, C. Droitcourt ${ }^{5}$, A. Perdriger ${ }^{1}$, C. M. Yelnik ${ }^{6}$, E. Hachulla ${ }^{7}$, V. Sobanski ${ }^{7}$, P. Jégo ${ }^{2}$, G. Coiffier ${ }^{8}$, A. Lescoat ${ }^{9} .{ }^{1}$ Rheumatology Dept Rennes University Hospital, 35203, Rennes, France., Rennes, France; ${ }^{2}$ Univ Rennes, CHU Rennes, Inserm, EHESP, Irset (Institut de recherche en santé, environnement et travail) - UMR_S 1085, F-35000 Rennes, France, Rennes, France; ${ }^{3}$ Department of Rheumatology, $\mathrm{CHU}$ de Rennes, ${ }^{16}$, Boulevard de Bulgarie, 35200 Rennes, France; Inserm NuMeCan UMR 1274, CIMIAD, University of Rennes, 35000 Rennes, France, Rennes, France; ${ }^{4} \mathrm{CHU}$ Rennes, Internal Medicine and Clinical Immunology Dpt F-35000 Rennes, France, Rennes, France; ${ }^{5}$ Dermatology Dept Rennes University Hospital, 35203, Rennes, France., Rennes, France; ${ }^{6}$ University Lille, INSERM U 995, CHU Lille, Centre de Référence des Maladies Autoimmunes Systémiques Rares du Nord et Nord-Ouest de France, Lille, France., Lille, France; ${ }^{7}$ University Lille, INSERM U 995, CHU Lille, Centre de Référence des Maladies Autoimmunes Systémiques Rares du Nord et Nord-Ouest de France, Lille, France., Lille, France; ${ }^{8} \mathrm{CHU}$ Rennes, University of Rennes, INSERM U 1241, Rennes, France., Rennes, France; ${ }^{9}$ Univ Rennes, CHU Rennes, Inserm, EHESP, Irset (Institut de recherche en santé, environnement et travail) - UMR_S 1085, F-35000 Rennes, France, Rennes, France

Background: Recent studies have highlighted that ultrasound (US) examination could offer a better assessment of hand manifestations of systemic sclerosis (SSc). Indeed, US allows a simultaneous evaluation of vascular, fibrotic and inflammatory hand features of the disease. Power Doppler US can especially explore macrovascular involvement characterized by an obliteration of digital arteries or ulnar arteries. UInar artery occlusion (UAO) is especially frequent in SSc patients and could be a relevant marker of the severity of SSc-associated vasculopathy. Among other hand manifestations of SSc, US evaluation can notably explore tenosynovial involvement such as fibrotic tenosynovitis (TS), which is considered to be SSc-specific.

Objectives: This study aims to assess the diagnostic performances of these hand US parameters for the diagnosis of SSc.

Methods: 244 patients with suspected SSc were consecutively included. They all had US evaluation assessing the presence of fibrotic TS and UAO. The final diagnosis of SSc was based on the evaluation of an expert, independently from US results and from any pre-established classification criteria

Results: 166 patients were finally diagnosed as SSc. 62 SSc and 8 non-SSc patients had UAO (uni or bilateral) $(p=0.001) .23$ SSc patients and 1 non-SSc patient had US fibrotic TS $(\mathrm{p}=0.007)$. A US SSc-pattern (presence of UAO and/or fibrotic TS) was reported in 73 SSc patients and 9 non-SSc patients $(p<0.001)$. UAO had an area under ROC curve (AUC) for the diagnosis of SSc of $0.618(95 \% \mathrm{Cl} 0.539-0.697)$; with $\mathrm{Se}=0.373(0.304-0.449)$ and $\mathrm{spe}=0.862$ 